ERIC MARCUS

\title{
MENTAL CAUSATION IN A PHYSICAL WORLD
}

\begin{abstract}
It is generally accepted that the most serious threat to the possibility of mental causation is posed by the causal self-sufficiency of physical causal processes. I argue, however, that this feature of the world, which I articulate in principle I call Completeness, in fact poses no genuine threat to mental causation. Some find Completeness threatening to mental causation because they confuse it with a stronger principle, which I call Closure. Others do not simply conflate Completeness and Closure, but hold that Completeness, together with certain plausible assumptions, entails Closure. I refute the most fully worked-out version of such an argument. Finally, some find Completeness all by itself threatening to mental causation. I argue that one will only find Completeness threatening if one operates with a philosophically distorted conception of mental causation. I thereby defend what I call naïve realism about mental causation.
\end{abstract}

Contemporary philosophers of mind work within the constraints imposed by the following platitude: Ours is a physical world. The question is then raised: Is there any work for mental causes to do in a physical world? This question is typically answered in one of two ways: naturalistically or skeptically. Amongst those who think that an affirmative answer is tenable, it is often assumed that such an answer requires naturalism - typically, in some form of identity theory or functionalism. Amongst those who think that an affirmative answer is untenable (perhaps because of the failure of the first strategy), the question gives rise to skepticism about mental causation - typically, in some form of epiphenomenalism or eliminativism. If these are our options, we are left with the following dilemma: Either mental causation just is (ultimately) physical causation, or it's nothing at all.

I think this reckoning leaves out a plausible and attractive option, which I have elsewhere called naïve realism about mental causation. ${ }^{1}$ According to this view, we can maintain an intuitively satisfying form of realism about mental causes while denying that the mind's efficacy can be reconstructed from ingredients provided 
by the natural sciences - while denying, that is, that mental causation can be naturalized.

In what follows, I will defend this view indirectly. More than any other factor, it is the causal self-sufficiency of physical causal processes that raise questions about the possibility of mental causation. ${ }^{2}$ I will argue, however, that this feature of the world, which I articulate in principle I call Completeness, in fact poses no genuine threat to mental causation. Some find Completeness threatening to mental causation because they confuse it with a stronger principle, which I call Closure. This confusion is the topic of Section I. Others do not simply conflate Completeness and Closure, but hold that Completeness, together with certain plausible assumptions, entails Closure. In Section II, I refute the most fully worked-out version of such an argument. Finally, some find Completeness all by itself threatening to mental causation. In Section III, I argue that one will only find Completeness threatening if one operates with a philosophically distorted conception of mental causation. I defend naïve realism, then, by arguing that the most plausible rationale for rejecting it fails.

Let me begin by distinguishing between a pair of principles: Completeness and Closure. According to Completeness, all physical events have complete physical causal histories. ${ }^{3}$ Completeness can be understood as the ontological version of the thesis that physics is in-principle completable, that there is some true physical theory capable of fully explaining why physical processes unfold in precisely the way they do. To say that a theory fully explains why physical processes unfold in the way they do is to say that at each stage in a physical causal chain, the causal connection between it and earlier and later stages can be completely accounted for by a true physical theory. The physical causal histories of physical events are complete in virtue of this fact about them; and, as far as we know, this property of physical causal histories is unique to them. ${ }^{4}$

This principle, however, is often confused with Closure. According to Closure, physical events cannot interact causally with non-physical events, or with physical events in virtue of their 
non-physical properties. Closure represents the physical world as cloistered from the influence anything non-physical: Nothing nonphysical can affect the physical. ${ }^{5}$

One can find these principles run together in a premise from David Lewis' famous argument for identity theory. The premise is "the plausible hypothesis that there is some unified body of scientific theories, of the sort we now accept, which together provide a true and exhaustive account of all physical phenomena (i.e., all phenomena describable in physical terms.)"6 This premise, Lewis, says,

does not rule out the existence of nonphysical phenomena: it is not an ontological thesis in its own right. It only denies that we need ever explain physical phenomena by non-physical ones. . . All manner of nonphysical phenomena may coexist with them, even to the extent of sharing the same space-time, provided only that the nonphysical phenomena are entirely inefficacious with respect to the physical phenomena. ${ }^{7}$

In the first part of this passage, this premise states that we never need to explain physical phenomena by non-physical ones. But to say that we don't ever need to causally explain physical phenomena by appealing to non-physical phenomena is not to say that we cannot causally explain physical phenomena by appealing to non-physical phenomena. ${ }^{8}$ The motion of every molecule may well be traceable back via the laws of physics to earlier motions of molecules, but the very same motions of molecules might also be traced back, via different kinds of causal principles, to a man's desire to eat lunch, or to the fall of Dow Jones Industrial Average, or to any number of other kinds of factors. The view that we don't need to depart from physical explanations to explain physical events is Completeness; the view that we necessarily go wrong in departing from physical explanations to explain physical events is Closure. The former is indeed plausible, but, by itself, also innocuous. The latter is dangerous - but it awaits an adequate justification. ${ }^{9}$

It is dangerous in the following important respect: To accept Closure would appear to make the problem of mental causation insoluble. If the mind cannot have physical effects, there is little reason to think it can have any effects at all. ${ }^{10}$ Davidson's famous solution to the problem of mental causation, according to which token mental events are identical to token physical events is of no 
help. Even if mental events are token-identical to physical events, Closure still excludes the possibility that mental events are efficacious qua mental. Their efficacy, according to Closure, is entirely due to their physical properties. The most natural way of reconciling Closure with the existence of mental causation is to hold that mental properties just are physical properties; and type-identity theory now seems plausible to almost no one.

But Closure surely requires justification. On its face, there is little to recommend it. On plausible assumptions, it entails that only a handful of human beings have ever causally explained anything, that no one, until quite recently, has ever really known why anything has happened. Knowledge of actual causal relations would be limited to those who correctly deploy true physical laws to explain events identified using the language of physical theory. Ordinary psychological explanations, in addition to those of geology, neuroscience, economics, computer science, aeronautical engineering, are all literally false. Implausible in its consequences, we ought to examine its credentials with the closest scrutiny before accepting it.

When we conflate Completeness and Closure, however, the nonexistence of mental causes appears to be a simple consequence of adopting a modest form of physicalism. Conversely, those who would defend the possibility of mental causation are branded as mystery-mongering enemies of science, useful only periodically to animate straw-men. For it seems that in rejecting Closure, they are thereby rejecting Completeness. Compounding the problem is the fact that some defenders of mental causation themselves apparently conflate Completeness and Closure, preferring to brave the naturalist inquisition by rejecting Completeness rather than give up on the view that the mind matters. Later, I will turn to one of these heretics. I will do so neither to join the inquisition nor to come to her defense. Rather, I hope to show that the mistake involved in rejecting Completeness goes deeper than its affront to science, accounting for a widespread distortion in philosophical conceptions of mental causation.

Until then, I shall be concerned to discuss the relationship between Closure and Completeness. Those who press the problem of mental causation, either in support of a skeptical or a naturalistic conclusion, need a route from Completeness to Closure. The first 
step towards finding this route is to recognize that they are distinct; the second, harder, step, is to formulate a clear and convincing argument that takes us from the truth of the one to the truth of the other. Let us now turn to such an argument.

In the literature on the problem of mental causation, we find two routes from Completeness to Closure, one short and one long. The short route can be summarized as follows. "To say that a physical event can have a complete physical causal history and other, non-physical causal histories as well, is to say that a physical event is overdetermined by its causes. Now, overdetermination does happen; but when it happens, it is the result either of coincidence or of design. The philosopher who accepts Completeness but rejects Closure must say that whenever a mental event has a physical effect, the physical effect in question is overdetermined. But that is to say that there exists in the world a widespread and systematic overdetermination of physical events. And that is preposterous."

Since I have argued elsewhere that this argument fails, I will give the short route short shrift here. ${ }^{11}$ Suffice it to say that such overdetermination is only implausible if the mental and the physical are conceived of as two self-sustaining and independent causal realms. It would be spooky only if the efficacy of mental states and events were conceived of as immune to physical events. But overdetermination is compatible with the counterfactual dependence of the mental on the physical. That is, one can hold both that a mental state has efficacy of its own, and also that, had things been different physically, it would not have had any effects at all. This threat to the possibility of distinctively mental causation is only apparent. We will, however, return to it a bit later.

The longer route will be my focus in this section; and it might be understood as a refinement and elaboration of the shorter argument just sketched. Intuitively, this way of linking Completeness and Closure goes like this. Completeness tells us that physical events have complete physical causal histories. It is also widely-held that putative mental causes of physical events are strongly dependent on underlying physical processes. Furthermore, for some physical 
event $\mathrm{P}$, its complete physical causal history will also be the physical basis for any putative mental cause of P. But if the same physical processes are responsible both for the putative mental cause of $\mathrm{P}$, and $\mathrm{P}$ itself, then what reason is there for thinking that mental causes are really doing any of the causal work? From this vantage point, mental causes appear as epiphenomena, correlated with the events that they are typically thought to cause, but only so correlated because they are reliable indicators of the real causes - viz., the physical properties and processes on which they depend.

This is the intuitive picture: compelling, but, I will argue, mistaken. In order to illustrate its mistakes, we will need to examine a relatively detailed rendition of the argument. Unfortunately, since the distinction between Completeness and Closure has gone largely (though not entirely ${ }^{12}$ ) unnoticed, few have attempted to provide one. In his most recent book, Mind in a Physical World, Kim formulates a ten-step dilemma-style argument against mental causation: "The Supervenience Argument."

As it is currently the most detailed version the argument sketched above, it merits close examination. My contention, however, will be that Kim's argument surreptitiously slides between what I have called Completeness and Closure at a number of key points. The most egregious instances of the Completeness/Closure conflation occur just at that point in the argument when Kim sets himself the task of providing an argument against overdetermination. As I shall argue below, his argument there is either ineffective (where physicalism is understood as entailing Completeness) or questionbegging (where physicalism is understood as entailing Closure).

It begins with

(i) Either mind-body supervenience holds or it fails. ${ }^{13}$

Kim will argue from here that, if supervenience is false, then there are no mental causes, and if supervenience is true, then, again, there are no mental causes.

Mind-Body supervenience is defined as follows:

Mental properties supervene on physical properties in the sense that if something instantiates any mental property $\mathrm{M}$ at $\mathrm{t}$, there is a physical base property $\mathrm{P}$, such that the thing has $\mathrm{P}$ at $\mathrm{t}$, and necessarily, anything with $\mathrm{P}$ at a time has $\mathrm{M}$ at that time. ${ }^{14}$ 
The substantive part of his argument begins with

(ii) If mind-body supervenience fails, there is no visible way of understanding the possibility of mental causation. ${ }^{15}$

What is the argument for (ii)? Kim says that the failure of supervenience would require violation of what he calls 'the causal closure of the physical'. What's that? Here's how he puts it:

If you pick any physical event and trace out its causal ancestry or posterity, that will never take you outside the physical domain. That is, no causal chain will ever cross the boundary between the physical and the non-physical. ... If you reject this principle, you are ipso facto rejecting the in-principle completeability of physics. ${ }^{16}$

The last sentence makes as it sound as if he has Completeness and not Closure in mind, but the earlier part of the passage is ambiguous. Tracing the causal ancestry of a physical event need not take us outside the physical domain; but it might if we let it. The idea that no causal chain will ever cross the boundary between the physical and the non-physical captures what I've called Closure; but accepting the idea that there might be such boundary-crossing does not require that we give up on Completeness. As in the case of Lewis above, I suspect that Kim's principle appears plausible only while he is representing it as Completeness; and when it packs a philosophical punch, he is representing it as Closure. I think this conflation is pernicious here: Kim says that "freely floating" mental events, i.e., those that don't supervene on physical events, would "obviously breach physical causal closure." 17 To allow such events, Kim holds, would be to understand the mental as "an ontologically independent domain that injects causal influences into the physical domain from the outside." 18 But merely allowing such influence does not require that we reject the in-principle completeability of physics: It does not require that we reject Completeness, but only Closure. Thus Kim has not shown that the falsity of supervenience would doom mental causation.

But his argument is largely focused on the other horn of the dilemma; and many find supervenience a plausible thesis. ${ }^{19}$ It would be bad enough, then, if he could show that Completeness plus Supervenience entails Closure. But the argument that constitutes this horn of the dilemma is also vitiated by a conflation of Completeness and Closure. Let's continue. 
(iii) Suppose that an instance of mental property $M$ causes another mental property $\mathrm{M}^{*}$ to be instantiated. ${ }^{20}$

Then, given that mind-body supervenience holds,

(iv) $\quad \mathrm{M}^{*}$ has a physical supervenience base $\mathrm{P}^{* 21}$

Remember, to say that $\mathrm{P}^{*}$ is the physical supervenience-base of $\mathrm{M}^{*}$ is to say that the occurrence of $\mathrm{M}^{*}$ is necessitated by the occurrence of $\mathrm{P}^{*}$. Kim then asks: "Where does this instance of $\mathrm{M}^{*}$ come from? How does $\mathrm{M}^{*}$ get instantiated on this occasion?" And he gives us two possibilities:

(v) $\quad \mathrm{M}^{*}$ is instantiated on this occasion (a) because, ex hypothesis, $M$ caused $\mathrm{M}^{*}$ to instantiated; (b) because $\mathrm{P}^{*}$, the physical supervenience base of $\mathrm{M}^{*}$, is instantiated on this occasion. $^{22}$

Kim sees a "real tension" between these two answers. Kim holds that if $\mathrm{M}^{*}$ is instantiated because $\mathrm{P}^{*}$ is instantiated, then it can't also be because $\mathrm{M}$ is instantiated. If there is a real tension here, then supervenience would indeed undermine the efficacy of the mental; Completeness would entail Closure. And although he makes some suggestive remarks intended to get us to see matters the way he does, I hope to show you that they fall short of the required argument.

Kim notes that

Under the assumption of mind-body supervenience ... so long as $\mathrm{P}^{*}$ occurs, $\mathrm{M}^{*}$ must occur no matter what events preceded this instance of $\mathrm{M}^{*}$ - in particular, regardless of whether or not an instance of $\mathrm{M}$ preceded it. ${ }^{23}$

Along the same lines:

As long as $\mathrm{P}^{*}$, or another base property of $\mathrm{M}^{*}$ is present, that absolutely guarantees the presence of $\mathrm{M}^{*}$, and unless such a base is there on this occasion, $M^{*}$ can't be there either. ${ }^{24}$

The fact that some $\mathrm{P}^{*}$ guarantees the presence of $\mathrm{M}^{*}$ does not, however, show that $\mathrm{M}$ was not a cause. For the counterfactual tie between $M$ and $M^{*}$ is at least as strong as the counterfactual tie between $\mathrm{P}^{*}$ and $\mathrm{M}^{*}$. Say, for example, my seeing a friend across the street prompts a desire to begin a conversation with her. We have a 
mental cause, the seeing, and a mental effect, the onset of the desire; and we have their actual supervenience bases, which I will continue to call $\mathrm{P}$ and $\mathrm{P}^{*}$ respectively. Now, think of the possible world where someone slips an extremely small quantity of a chemical $\mathrm{C}$ in my drink during the evening prior to $\mathrm{M}$. Let us imagine, further, that in this possible world, my brain contains a harmless level of $\mathrm{C}$ the next day, though it makes no difference to thoughts and behavior relevant to $\mathrm{M}$ and $\mathrm{M}^{*}$. Let us suppose that $\mathrm{C}^{\text {'s }}$ effect on my brain is to leave it functionally unchanged (in respects relevant to these mental states at least), while altering the way the relevant bits of my brain's functional organization are implemented. In this possible world, $M$ occurs, as does $M^{*}$, but they have different supervenience bases. They have different supervenience-bases because the physical events that guarantee the presence of $\mathrm{M}^{*}$ contain different physical constituents. $^{25}$

The point, of course, is not that the brain is irrelevant to $\mathrm{M}^{*}$, but that in possible worlds close to ours where $\mathrm{M}^{*}$ occurs, the presence of $\mathrm{M}$ is fairly constant, whereas the presence of $\mathrm{P}^{*}$ is not. I could have been physically different in all kinds of ways (corresponding to all of the possible scenarios for which the $\mathrm{C}$-example provides a schema), irrelevant to the onset of my desire to talk to my friend. Thus, even if $\mathrm{P}^{*}$ hadn't occurred, $\mathrm{M}^{*}$ might well have. But if $\mathrm{M}$ doesn't occur, then $\mathrm{M}^{*}$ doesn't occur no matter what.

No doubt this is too strong. $\mathrm{M}^{*}$ might have occurred, even if $\mathrm{M}$ had not: There are those worlds where I come to desire a conversation with my friend even though I haven't seen her across the street, perhaps because her name has appeared on the 'caller-ID' window of my cell-phone. This non-M world is, perhaps, still an $\mathrm{M}^{*}$ world. And so it is perhaps false to say, as we did at the end of the last paragraph, that if $\mathrm{M}$ doesn't occur, then $\mathrm{M}^{*}$ doesn't occur no matter what. It might thus seem that $\mathrm{M}$ and $\mathrm{P}^{*}$ are at least on equal footing, counterfactually speaking, with respect to $\mathrm{M}^{*}$.

This equal footing may well be enough to fend off threats to the causal connection between $\mathrm{M}^{*}$ and $\mathrm{M}$ posed by $\mathrm{P}^{*}$. But I believe we can make an even stronger claim. If we assume that $\mathrm{P}$ is a nomologically necessary condition of $\mathrm{P}^{*}$, then we can also say the following: In all of the nomologically possible worlds where $\mathrm{P}^{*}$ subvenes $\mathrm{M}^{*}, \mathrm{M}$ causes (or in any case appears to cause) $\mathrm{M}^{*}$. 
Since, on our assumption, $\mathrm{P}^{*}$ only occurs because $\mathrm{P}$ did, and since, according to mind-body supervenience, $\mathrm{P}$ requires $\mathrm{M}$, all of the $\mathrm{P}^{*}$ worlds are $\mathrm{M}$ worlds. But the converse is not true. That is, not all the worlds where $M$ causes (or in any case appears to cause) $M^{*}$ are worlds where $\mathrm{P}^{*}$ subvenes $\mathrm{M}^{*}$.

Thus, the mental cause and effect have a stronger counterfactual tie than the mental effect and its physical supervenience base. All of the nearby worlds in which $\mathrm{P}^{*}$ helps to explain $\mathrm{M}^{*}$ are worlds in which $\mathrm{M}$ helps to explain $\mathrm{M}^{*}$. But some worlds in which $\mathrm{M}$ helps to explain $\mathrm{M}^{*}$ are not worlds in which $\mathrm{P}^{*}$ helps to explain $\mathrm{M}^{*}$. The fact that I saw my friend thus seems more important to my wanting to talk to her than does the fact that I was in exactly the physical state that I was.

Kim is right that some supervenience-base for $\mathrm{M}^{*}$ must have occurred. But why should this neutralize the causal significance of M? Consider the set of possible physical supervenience bases for $\mathrm{M}^{*}$. One member of this set occurred. Now we can ask: What explains the fact that a member of this set occurred? And if we look across the worlds where a member of this set occurs, we find that all or most have something in common (something other than the occurrence of $\mathrm{M}^{*}$ ), viz., the occurrence of $\mathrm{M}$. This gives at least a prima facie reason for thinking that $\mathrm{M}$ is a cause of whatever member of that set occurs, and to that extent can justifiably be considered a cause of $\mathrm{M}^{*}$ 's supervenience base, whatever it might be. But if $\mathrm{M}$ is itself a cause of $\mathrm{P}^{*}$, then, no matter how important $\mathrm{P}^{*}$ is for $\mathrm{M}^{*}$, it cannot undermine M's efficacy.

Recall that the point of the 'Supervenience Argument' is to make explicit the incompatibility between physicalism and mental causation. Kim's justification for the claim that the two answers cited in (5) are in tension would make this case, for such a tension would, under the assumption of mind-body supervenience, have to be decided in favor of $\mathrm{M}^{*}$ 's supervenience base $\left(\mathrm{P}^{*}\right)$ at the expense of its putative cause (M). We have seen, however, that there is a tension here only if $\mathrm{M}$ is not a cause of $\mathrm{P}^{*}$.

Kim, of course, ultimately denies that $\mathrm{M}$ is a cause of $\mathrm{P}^{*}$. On what grounds? To answer this question, we move to

(vi) $\quad \mathrm{M}$ caused $\mathrm{M}^{*}$ by causing $\mathrm{P}^{*}$. That is how this instance of M caused $M^{*}$ to be instantiated on this occasion. ${ }^{26}$ 
(vi) is ambiguous. On a weak interpretation, it expresses what I take to be an important truth: If $\mathrm{M}$ causes $\mathrm{M}^{*}$, and $\mathrm{M}^{*}$ supervenes on $\mathrm{P}^{*}$, then $\mathrm{M}$ must also be a cause of $\mathrm{P}^{*}$. For the purposes of Kim's argument, the weaker interpretation will do. But it is important not to mistake this for a stronger claim. On the stronger interpretation, (vi) says that the causal connection between $\mathrm{M}$ and $\mathrm{M}^{*}$ is in some sense exhausted by the causal relation between $\mathrm{M}$ and $\mathrm{P}^{*}$. But (vi) on this stronger interpretation gets things backward. If anything, the causal relation between $\mathrm{M}$ and $\mathrm{P} *$ is comparatively weak, as $\mathrm{M}$ explains not why $\mathrm{P}^{*}$ in particular occured, but why some supervenience-base or another for $\mathrm{M}^{*}$ occurred. Indeed, we might even say that $\mathrm{M}$ causes $\mathrm{P}^{*}$ in virtue of $\mathrm{P}^{*}$ 's being one among many $\mathrm{M}^{*}$-correlates, and thus that $\mathrm{M}$ causes $\mathrm{P}^{*}$ in virtue of causing $M^{*}$. We will revisit this point later, but for now I will return to discussing its place in Kim's overall argument.

The purpose of (vi) and its justification is (at least) to establish that it is a necessary condition for M's causing $M^{*}$ that it also cause $\mathrm{P}^{*}$. Let us grant this. Kim now sets out to show that $\mathrm{M}$ could not be a cause of $\mathrm{P}^{*}$, and thus that $\mathrm{M}$ could not be a cause of $\mathrm{M}^{*}$. If Kim can indeed show this, the Supervenience Argument (well, at least the second and more important horn) would be effective and would establish a compelling route from Completeness to Closure. Let's see how Kim makes this case.

First, he notes

(vii) $\quad \mathrm{M}$ itself has a physical supervenience base $\mathrm{P}^{27}$

Kim claims that if we reflect on the causal status of $\mathrm{M}$ and $\mathrm{P}$ with respect to $\mathrm{P}^{*}$, we will "see reasons for taking $\mathrm{P}$ as preempting the claim of $\mathrm{M}$ as a cause of $\mathrm{P}^{*}$." ${ }^{28} \mathrm{He}$ considers a number of ways of avoiding seeing $\mathrm{P}$ as preempting the claim of $\mathrm{M}$ as a cause of $\mathrm{P}^{*}$, and argues in turn that each of these ways is unworkable. Since I agree with him about the deficiencies of some of these ways, I will focus on his criticism of what I take to be the successful way of avoiding seeing $\mathrm{P}$ as preemptory.

I think we ought to view $\mathrm{M}$ and $\mathrm{P}$ as overdetermining $\mathrm{P}^{*}$. What's wrong with the view that physical events are overdetermined? Well, Kim first says that it is "implausible." ${ }^{29}$ This is simply the short route from Completeness to Closure, sketched in section II. It would certainly be implausible if independent causal sequences 
were routinely overdetermining physical events: If, for example, whenever a tree fell in the forest, it was the result of both sawing and lightning, or lightning and a larger tree knocking it down, or a larger tree knocking it down and a ferocious assault by woodpeckers. But overdetermination by mental and physical causes typically isn't like this. For mental causes are dependent on underlying physical processes.

It will often be true that a significant disruption in the physical causal process would render the mental cause non-existent or impotent. This follows from the thesis of supervenience: if the physical processes are disturbed to the extent of excluding the occurrence of a supervenience base for the mental event in question, the mental event will not occur. So, admitting this kind of overdetermination would not commit one to the view that mental causes would have their physical effects irrespective of ongoing physical processes. For that matter, it would not commit one to the view that the physical causes could have their physical effects irrespective of ongoing psychological processes. Overdetermination by mental and physical causes, then, cannot be rejected so easily.

Let's consider Kim's other strategy for discrediting overdetermination. He says that, "in making a physical cause available to substitute for every mental cause, it appears to make mental causes dispensable in any case." 30 What does it mean to say that mental causes are dispensable? Perhaps it means simply that we can account for $\mathrm{P}^{*}$ without bringing in $\mathrm{M}$. This is true, but it can't, or in any case shouldn't, be what Kim is here saying. An argument against this sort of overdetermination should explain why, in my terminology, Closure follows from Completeness. Merely invoking Completeness is of no help, for Completeness by itself does not rule out overdetermination. Completeness just says that we don't need to cite non-physical causes to account for a physical event, not that there are no non-physical causes.

Perhaps by "dispensable", he means that, had M not occurred, $\mathrm{P}^{*}$ would have occurred anyway. But this will not typically be so. Had I not seen my friend, I would not have been in the physiological state on which my seeing supervened, and thus the subsequent physical causal processes would have differed as well. 
Perhaps, by "dispensable", he is gesturing in the direction of the following fact: So long as $\mathrm{P}$ occurred, then, whether or not $\mathrm{M}$ occurred, $\mathrm{P}^{*}$ would have occurred. But if this were enough to exclude $\mathrm{M}$ from being a cause of $\mathrm{P}^{*}$, then it would rule out as causes almost everything that everyone, scientists and common folk alike, would consider a cause. For it would render causation an intransitive relation. If the shooting was causally sufficient for the death, and the death was causally sufficient for the fall of the monarchy, then, whether or not the shooting occurred, the death would have caused the fall of the monarchy. Does this show that the shooting did not cause the fall of the monarchy? Of course not. I am not proposing that $\mathrm{P}$ is a causal intermediary between $\mathrm{M}$ and $\mathrm{P}^{*}$. Rather, $\mathrm{I}$ am pointing out that it does not undermine M's status as a cause that, so long as $\mathrm{P}$ occurs, then whether or not $\mathrm{M}$ occurs, $\mathrm{P}^{*}$ occurs.

There is another serious problem with Kim's argument on this last interpretation. What does it mean to say that, so long as $\mathrm{P}$ occurred, then, whether or not $\mathrm{M}$ occurred, $\mathrm{P}^{*}$ would have occurred? If $\mathrm{P}$ is a supervenience base of $\mathrm{M}$, as we have been supposing, then P's occurrence is sufficient for M's occurrence. A world in which $\mathrm{P}$ occurs, but $\mathrm{M}$ does not, is a world that is governed by very different causal laws than ours. It is questionable whether $\mathrm{P}$ could even occur in such a world, and it is questionable whether, even if it could occur, it would have $\mathrm{P}^{*}$ as a consequence. ${ }^{31}$

Kim needs an argument to show that a putative cause $M$ of a mental event $\mathrm{M}^{*}$ could not be an overdetermining cause of $\mathrm{M}^{*}$ 's supervenience-base $\mathrm{P}^{*}$. Without one, the argument founders.

(viii) $\quad \mathrm{P}$ caused $\mathrm{P}^{*}$, and $\mathrm{M}$ supervenes on $\mathrm{P}$ and $\mathrm{M}^{*}$ supervenes on $\mathrm{P}^{*} .32$

The point of (viii) is to set up:

(ix) The M-to-M* and $\mathrm{M}$-to-P* causal relations are only apparent, arising out of a genuine causal processes from $\mathrm{P}$ to $\mathrm{P*} .33$

But if (ix) only follows from (viii) if Kim has ruled out the possibility that $\mathrm{M}$ and $\mathrm{P}$ overdetermine P*. Since he hasn't successfully done this, I don't believe he is entitled to (ix). Hence I reject both conjuncts of 
(x) If mind-body supervenience fails, mental causation is unintelligible; if it holds, mental causation is again unintelligible. $^{34}$

III

Perhaps this argument leaves you with a bad taste in your mouth. Perhaps you are thinking: "Well, it may be that Kim's arguments fail to establish Closure on the basis of Completeness. But even if even if no such argument works, don't we want more for mental causation than you're giving us? Aren't we defending common sense only if we resist arguments against mental causation by claiming that mental causes can pick up some of the causal slack left by physical processes? And if physical processes leave no causal slack, then there is, of course, none left for mental causes to pick up."

In what remains, I will attempt to combat the suspicion behind this sort of thought. I will do so by considering what sort of view of mental causation emerges when we think of mental causes as 'filling in the gaps' in physical causal chains, as thereby requiring violations of Completeness. Although this view is motivated by a desire to represent the common sense view of the efficacy of the mind, I will argue that, in fact, it has little in common with the way we commonsensically think about the mind's power to affect the world. I thus hope at least to diminish any lingering suspicion that somehow mental causation really does require the falsity of Completeness.

Lynne Rudder Baker holds that we ought to reject Completeness. In "Metaphysics and Mental Causation", she argues that Completeness will "render unwarranted any attempt to explain what we do by what we think, subvert our ordinary causal notions that are constitutive of law, morality, and everyday life, ... [and also] make a mockery of the causal claims and explanations of the special sciences." ${ }^{35}$ On her view, once one accepts the metaphysical thesis that physical events have complete physical causal histories, there is no room left in our causal picture of the world to accommodate any non-physical causes. Her strategy for resolving the problem is to subordinate the metaphysics of causation (of which Completeness is an example) to explanatory practice: 
For example, when Jill returns to the bookstore to retrieve her keys, what she thinks affects what she does in virtue of the following explanatory fact: if she hadn't thought that she had left her keys, then, other things being equal, she wouldn't have returned to the bookstore; and given that she did think that she had left her keys, then, other things being equal, her returning was inevitable. ${ }^{36}$

For Baker, such explanatory facts trump the metaphysical theses that she takes to be incompatible with them. A metaphysics according to which people never act because of what they think couldn't possibly be right, as our reasons for believing it could never be stronger that our reasons for thinking that the mind makes a causal difference. Completeness, she thinks, entails epiphenomenalism, so Completeness must be false. ${ }^{37}$

As anticipated earlier, however, her proposal is apt to attract scorn for being at odds with a contemporary understanding of the physical world. As Kim puts it:

To give up [Completeness] is to acknowledge that there can be in principle no complete physical theory of physical phenomena, that theoretical physics, insofar as it aspires to be a complete theory, must cease to be pure physics and invoke irreducible nonphysical causal powers - vital principles, entelechies, psychic energies, élan vital, or whatnot. ${ }^{38}$

Viewing $\mathrm{P}$ as a partial cause thus requires that physical processes (sometimes) need help from mental causes to get where they're going, that mental causes intervene somehow in physical processes to give them the push they (sometimes) need. To disavow the thought that physical events have complete physical causal histories is, in effect, to hold that there are no strict laws governing physical phenomena. For we would then have to acknowledge that there are some physical events whose occurrence (or whose chances of occurrence) are not determined by physical laws. And many find this too steep a price to pay even to save us from epiphenomenalism.

If we leave the argument here, it seems that Baker has better represented the commonsense view of mental causation; and Kim has shown us that such a view, though appealing to common sense, is incompatible with a proper appreciation of the fact that our world is a physical one. We are then faced with an uncomfortable choice between common sense and science. And, lest we be accused of intellectual faint-heartedness, we will likely reject Baker's defense 
of mental causation. But there is a better reason for rejecting Baker's view than its incompatibility with science.

The deeper problem with Baker's view is that it yields an implausible conception of mental causation, one which has little to do with common sense. Mental causation, on this view, crucially involves the causation of physically inexplicable physical motion. This suggests that the only thing we ought to count as a distinctively mental cause is something that impinges on physical processes in the way physical forces do, but which is after all non-physical. By thinking of mental causes as picking up the causal slack left by physical causes, we adopt what we may call the telekinetic view of mental causation: i.e., mental causation as some kind of spiritual pushing. To put it colorfully: On this view, we stand to our bodies, or perhaps just to our brains, in the same relation that Yuri Geller purports to stand to his fabulous bending spoons.

Take, for example, the motion of a particle of my thumb. If Baker is right, when I intentionally raise my hand, there is some moment or moments in the etiology of this particle's rise that are (at least in part) mysterious from the perspective of the physical sciences. These sciences are either completely silent on the question of which of several paths a particle will travel along or make predictions about its trajectory that prove to be false. The mental cause thus alters the particle's trajectory, as perhaps the wind might alter the course of a soundly-hit tennis ball.

This picture of mental causation is not a faithful representation of what's implicit in our ordinary explanatory practice, but rather a philosophical distortion. The distortion comes in part as a result of thinking that mental causation, if it be causation at all, must work the way physical causation does. Under the influence of this distortion, we expect to find the same kind of evidence for the presence of mental causes as we find for the presence of physical causes. If the operation of physical causation is detectable on the basis of the behavior of lone molecules, flitting one as opposed to another way, so should the operation of mental causation. But there is no commonsensical reason to think that we can distinguish genuine from merely apparent psychological causation by attempting to discern physically inexplicable atomic motion. Were I interested in scrutinizing Yuri Geller's supernatural pretensions, I 
would devise and conduct experiments that test for the occurrence of such motion. But such tests do not bear at all on the question of the existence of (ordinary) mental causation. As far as I know, no one has ever thought to test for the existence of mental causation using such an experiment. And that is because when I think, for example, that someone crossed the street because he wanted to talk to a friend, I do not see him as having been blown into the street by some kind of ghostly wind. But if such experiments are commonsensically thought to be irrelevant to mental causation, then the common sense view of mental causation does not require violations of Completeness.

The telekinetic view of mental causation is the idea that we should adopt the following constraint on mental causes: Mental causes must cause physical motion that is underdetermined by physical causes. My proposal, then, is that we should reject the telekinetic view of mental causation, and that, once we do, we can accept the compatibility of mental causation and Completeness without a guilty conscience.

I will conclude by considering a pair of objections. First, it will be objected that I have based much of my argument in this section on the deliverances of common sense. Throughout this section, I have repeatedly invoked features of the commonsense conception of mental causation, and wielded this conception against those who doubt the existence of mental causation. But common sense may well be mistaken about mental causation, and my arguments have no provisions to account for this possibility.

This objection is, however, misplaced. This section is devoted to responding to the complaint that my defense of mental causation runs afoul of common sense. Solutions to the problem of mental causation such as the one I'm advocating are accused of not giving mental causes any genuine causal punch, of the sort we ordinarily take them to have. My point here is that we don't ordinarily take them to have any punch - at least if this means that they operate in the first instance by jostling our bodies. My reliance on a common sense conception of mental causation in making this point is obligatory.

These remarks do not, of course, constitute an argument in favor of the common sense view. To argue that this view is correct, one 
would have to show that physicalism about the mind in all its forms is false; and it is no part of my aim here to show any such thing. If mental states, events and properties just were physical, then they would pack whatever punch physical states, events and properties do. My point can be put this way: If mental properties, for example, are not physical - and virtually no one thinks they are - then there is no commonsensical reason to think that their efficacy must be the spiritual analogue of the efficacy of physical properties, and thus no commonsensical reason for thinking they would require violations of Completeness. The view that mental causation must be physical causation thus cannot be supported simply by appealing to the fact that non-physical forces would be too spooky; and so an argument that mental properties are not identical to physical properties does not show that mental properties are inefficacious.

Second, it might be objected here that my conception of mental causation is really nothing more than a recasting of the position Davidson first attacked in "Actions, Reasons, and Causes."39 According to this view, mental events do not cause actions at all, rather they only rationalize actions. Although I am calling beliefs and desires causes, the objection might go, they do not deserve to be so called given my rejection of the telekinetic account of mental causation.

But the philosophically interesting question that drives debates about mental causation is just whether mental items matter to what happens. (A brief scan through the titles mentioned in note two above confirms this thought.) My use of 'causation' and its cognates here is intended to stand in for this relation of mattering to what happens. My thesis is thus that not all mattering to what happens should be conceived of in terms of the involvement of forces and the like. If someone wishes to deny that this kind of mattering is really causation, I am happy to give up using the term this way. But I will then insist that the problem of mental causation is misnamed: for nothing of urgent philosophical interest hangs on the question of whether mental items impact physical processes in the same way that physical items do - at least until this way of mattering is established as the only way of mattering to what happens.

We see here, then, a very peculiar feature of the debate surrounding the problem of mental causation. On the one hand, intuitively, 
we think that intentions, desires, and beliefs make a difference, and make a difference as such. This, in turn, leads to dissatisfaction with attempts to solve the problem of mental causation while retaining the view that physical causal processes are causally self-sufficient. But then, on the other hand, when we attempt to make room for mental causes by postulating gaps in physical causal processes, we are led to the peculiar telekinetic view of mental causation. Mental states and events then seem either to matter not at all, or to matter in the wrong way. Clearly, something has gone wrong.

Once we've recognized that we needn't think of mental causation as the spiritual version of physical causation, we are in a position to see that mental causation in no way requires the falsity of Completeness - indeed, this would just make mental causation a spooky affair. There is thus no reason to be dissatisfied with those attempts to solve the problem of mental causation that retain the view that physical causal processes are causally self-sufficient, and also no reason to doubt the significance of arguments that would block the inference from Completeness to Closure.

\section{CONCLUSION}

It will not have escaped the reader's notice that I have nowhere attempted to answer the following question: How do mental causes matter to what happens, if not telekinetically? Don't we still need an answer to this question?

Perhaps. But my purpose here has just been to show that even a robust form of physicalism (constituted by Completeness and Mind-Body Supervenience) poses no problem for mental causation. Philosophical accounts of mental causation have derived their urgency, and much of their interest, by casting themselves as responding to this perceived threat. Indeed, this is the point of these accounts. But if physicalism in fact poses no problem, then the purpose of a philosophical account of mental causation must again be made clear. In my view, questions about how mental causes matter should be understood as questions about the physiological mechanisms that make thinking possible. A scientific investigation of this sort, however, is not obviously philosophical at all. Regardless of the outcome of this investigation, the tenability of mental 
causation should no longer be thought to hang on the success of the philosophical project of naturalizing the mind.

In arguing against the view that Completeness entails Closure, I have shown that efficacy ascribed to the mental need not come at the expense of efficacy ascribed to the physical. In disputing the view that common sense commits us to a telekinetic conception of mental causation, I have removed any remaining motivation for denying Completeness. We thereby recognize the possibility of naïve realism about mental causation. Mental causation is real, poses no threat to the platitude that we live in a physical world, but nonetheless does not consist simply in physical causation.

I would like to thank Kelly Jolley, Ram Neta, Michael Watkins and an anonymous referee at this journal for helpful comments on previous drafts of this paper.

\section{NOTES}

1 See Marcus, 2001.

2 This problem of mental causation is often referred to as the problem of exclusion'. See Kim, 1993, especially essay 13; Lepore and Loewer, 1987, 1989; Fodor, 1989; Johnston, 1985; Block, 1995; Yablo, 1992; Van Gulick, 1992; Robb, 1997.

3 Throughout this paper, I use "physical" and its cognates as variations on "physics". There is still a thorny question, however, about what exactly a physical property is and how, precisely, physical properties are to be distinguished from mental properties. In Crane and Mellor (1990), the authors argue that "there is no divide between the mental and the non-mental to set physicalism up as a serious question" (p. 206), and thus also no way to make a principle such as Completeness meaningful. (More recently, Barbara Montero has argued for a similar view in Montero, 1999. See also Barry Stroud's discussion in Stroud, 2000, chapter three.) If this claim is correct, then the problem of mental causation simply does not get off the ground. I will assume, however (as Crane himself does in Crane, 1995) that there is some way of saying what is meant by 'physics', and that mental properties will not fall into the domain of physics, so understood. It also might be argued that Completeness cannot be motivated by a proper understanding of physical theories. If not, this problem of mental causation does not get off the ground. I do not take a stand here on this issue. My argument here can thus be understood as having the following form: Even if Completeness is both meaningful and true, the problem of mental causation can be satisfactorily resolved.

4 This does not mean that every physically describable state of affairs is causally determined by prior physical states of affairs, nor does it mean that every feature 
of every physical event has a cause. Famously, there are significant correlations between the events in spatially disparate quantum mechanical systems that have no common cause. Completeness says only that one need never depart from descriptions of the physical in order to account for what happens there. The just-mentioned correlations would only violate the causal completeness of the physical if there were some reason to think that they were the result of non-physical intervention. Also, it may be that there are some physical events that have no causes at all. If so, we can modify Completeness slightly while leaving these arguments intact. The modified version might go: All physical events either have complete physical causal histories or have no causal histories at all.

5 Perhaps the slide from Completeness to Closure should not be surprising. It may just reflect a confusion of two ways of understanding the notion of a 'complete causal history.' In one sense, a complete causal history would be one that requires no supplementation (this is roughly how I define it above); in a second sense, a complete causal history is one that contains all of the causes of an event.

6 Lewis, 1983, p. 105.

7 Ibid.

8 Throughout this paper, I treat the relationship between causation and causal explanations as follows. A causally explains B if and only if A causes B. This view is of course tendentious. Some, such as Dennett, hold that causal explanations can be literally true, even where the events (or facts) cited do not, strictly speaking, stand in a causal relations. See Dennett, 1987. And it is a philosophical commonplace that it might be true that A causes B, and yet false that citing A could causally explain B. In this paper, I am concerned primarily with a metaphysical issue: whether the mind matters. If the mind doesn't matter, the view that we can still correctly deploy psychological causal explanation would be, in my view, small consolation. And if the mind does matter, the view that we nonetheless cannot explain physical events (or facts) by appealing to mental events (or facts) should be no cause for concern. Thus my tendentious assumption is harmless. Additionally, this assumption will make exposition of Kim's view simpler, since this appears to be how he uses the expressions 'cause' and 'causally explain'. (He is explicit only in one direction, however: A causally explains B, only if A causes B. See Kim, 1998, pp. 64, 75-76.)

9 Among the philosophers, in addition to Lewis and Kim who have attempted to formulate principles in the vicinity of Completeness and Closure (either explicitly or implicitly) are McLaughlin in his, 1989, p. 115; Papineau in his, 1990, p. 67; Robb in his, 1997, pp. 182-184; and Yablo in his, 1992, p. 247.

10 There are those who would disagree. See, for example, Yablo, 1992.

11 See note 1. Two other recent attempts to solve the problem of mental causation by accepting some form of systematic overdetermination are Mills (1996) and Garrett (1998).

12 See, for example, Robb, 1997.

13 Kim, 1998, p. 39.

14 Ibid., p. 39. 
15 Ibid., p.40.

16 Ibid.

17 Ibid., p. 41.

18 Ibid.

19 It is not obvious that many would find it compelling as just defined, however. To the extent that one finds psychological externalism plausible, one will find mind-body supervenience implausible. If Kim cannot relax his definition so as to accommodate externalist considerations, then the first, rather neglected, horn of his dilemma will become much more important.

20 Ibid.

21 Ibid., p. 42.

22 Ibid.

23 Ibid.

24 Ibid.

25 My argument against Kim here relies (as does Kim's own) on (1) the falsity of the doctrine of token identity, and (2) the tenability of the view that an event might occur in more than one possible world. Kim argues for (1) in Kim, 1993, chapter 3. I argue for (1) very differently in Marcus, 2003. While I do not argue for (2), I suspect the thrust of the argument could be preserved by a more torturously formulated argument that did not make this assumption.

26 Op. cit., p. 42.

27 Ibid., p. 43.

28 Ibid.

29 Ibid.

30 Ibid., pp. 44-45.

31 I've omitted discussion of the following argument, as I think it adds nothing to what's already been said: "Consider a world in which the physical cause does not occur and which in other respects is as much like our world as possible. The overdetermination approach says that in such a world, the mental cause causes a physical event - namely, that principle of causal closure of the physical domain no longer occurs" (ibid., p. 45). This rather elliptical argument seems to come to this: In the closest possible world to ours in whihe $\mathrm{P}$ does not occur, but in which $\mathrm{M}$ causes $\mathrm{M}^{*}$, there is no physical cause for $\mathrm{M}^{*}$ 's supervenience-base. For reasons I've given above, I see no reason to suppose this: The closest possible world to ours in which $\mathrm{P}$ does not occur is either a world in which $\mathrm{M}$ does not occur, or some other supervenience bases for $\mathrm{M}$ and $\mathrm{M} *$ do occur.

32 Ibid., p. 45.

33 Ibid.

34 Ibid., p. 46.

35 Baker, 1993, p. 90.

36 Ibid., p. 93.

37 For a more direct attack on Completeness, see Lowe, 1992 and 1993.

38 Kim, 1993, p. 356.

39 Davidson, 1980. 


\section{REFERENCES}

Baker, L.R. (1993): 'Metaphysics and Mental Causation', in Heil and Mele (1993).

Block, N. (1995): 'Can the Mind Change the World?', in Macdonald (1995).

Crane, T. and Mellor, D.H. (1990): 'There is No Question of Physicalism', Mind 99, 185-206.

Crane, T. (1995): 'Mental Causation', Proceedings of the Aristotelian Society 69(Suppl.), 211-236.

Davidson, D. (1980): Essays on Actions and Events, New York: Oxford University Press.

Dennett, D. (1987): The Intentional Stance, Cambridge, MA: MIT Press.

Fodor, J. (1989): 'Making the Mind Matter More', Philosophical Topics XVII(1), 59-79.

Garrett, B.J. (1998): 'Pluralism, Causation, and Overdetermination', Synthese 116, 355-378.

Heil, J. and Mele, A. (eds.) (1993): Mental Causation, New York: Oxford University Press.

Honderich, T. (1982): 'The Argument for Anomalous Monism', Analysis 42(1), 59-64.

Johnston, M. (1985): 'Why Having a Mind Matters', in Lepore and McLaughlin (1985), pp. 408-426.

Kim, J. (1993a): Supervenience and Mind, Cambridge: Cambridge University Press.

Kim, J. (1998): Mind in a Physical World, Cambridge, MA: MIT Press.

Lepore, E. and Loewer, B. (1987): 'Mind Matters', Journal of Philosophy 84, 630-642.

Lepore, E. and Loewer, B. (1989): 'More on Making the Mind Matter', Philosophical Topics XVII(1), 175-191.

Lepore, E. and McLaughlin, B. (eds.) (1985): Actions and Events: Perspectives on the Philosophy of Donald Davidson, New York, NY, USA: B. Blackwell.

Lewis, D. (1966): 'An Argument for the Identity Theory', Journal of Philosophy 63, 17-25

Lowe, E.J. (1992): 'The Problem of Psychophysical Causation', Australian Journal of Philosophy 70(3), 263-276.

Lowe, E.J (1993): 'The Causal Autonomy of the Mental', Mind 102, 629644.

Marcus, E. (2001): 'Mental Causation: Unnaturalized, but not Unnatural', Philosophy and Phenomenological Research 63(1), 57-83.

Marcus, E. (2003): 'Events, Sortals, and the Mind-Body Problem', manuscript.

Macdonald, C. (1995): Philosophy of Psychology: Debates on Psychological Explanation, Cambridge: Basil Blackwell.

McLaughlin, B. (1989): 'Type Epiphenomenalism, Type Dualism, and the Causal Priority of the Physical', in Philosophical Perspectives, Vol. 3: Philosophy of Mind and Action Theory. 
Mills, E. (1996): 'Interaction and Overdetermination', American Philosophical Quarterly 33(1), 105-117.

Montero, B. (1999): 'The Body Problem', Nous 33(2), 183-200.

Papineau, D. (1990): 'Why Supervenience?', Analysis 50, 66-71.

Robb, D. (1997): 'The Properties of Mental Causation', The Philosophical Quarterly 47(187), 178-194.

Sosa, E. (1984): 'Mind-Body Interaction and Supervenient Causation', in Midwest Studies in Philosophy, vol. 9 (pp. 271-282), Minnesota: University of Minnesota Press.

Stoutland, F. (1985): 'Davidson on Intentional Behavior', in Lepore and McLaughlin (1985), pp. 44-59.

Stroud, B. (2000): The Quest For Reality, Oxford: Oxford University Press.

Van Gulick, R. (1992): 'Three Bad Arguments for Intentional Property Epiphenomenalism', Erkenntnis 36(3), 311-331.

Yablo, S. (1992): 'Mental Causation', The Philosophical Review 101(2), 245-280.

Department of Philosophy

Auburn University

6090 Haley Center

Auburn AL 36849

USA

E-mail: eric_marcus@yahoo.com 